\title{
Traumatic Injury and Atrial Fibrillation Among Deployed Service Members
}

\author{
Karl Christian Alcover ${ }^{1}$, Shiva Ambardar ${ }^{1}$, Eduard Poltavskiy ${ }^{2}$, Javed Nasir ${ }^{3}$, Jud Janak ${ }^{4}$, \\ Jeffrey Howard ${ }^{5}$, Lauren Walker ${ }^{2}$, Mark Haigney ${ }^{1}$, and Ian Stewart ${ }^{1}$ \\ ${ }^{1}$ Uniformed Services University of the Health Sciences \\ ${ }^{2}$ David Grant Medical Center \\ ${ }^{3}$ Stanford University School of Medicine \\ ${ }^{4}$ Bexar Data Limited \\ ${ }^{5}$ The University of Texas at San Antonio
}

April 29, 2021

\begin{abstract}
Introduction. Atrial Fibrillation and Atrial Flutter (AF/AFL), the most common atrial arrhythmias, have never been examined in combat casualties. In this study, we investigated the impact of traumatic injury on AF/AFL among service members with deployment history. Methods. Sampled from the Department of Defense (DoD) Trauma Registry ( $\mathrm{n}=10,000)$, each injured patient in this retrospective cohort study was matched with a non-injured service member drawn from the Veterans Affairs/DoD Identity Repository. The primary outcome was AF/AFL diagnosis identified using ICD-9-CM and ICD-10-CM codes. Competing risk regressions based on Fine and Gray subdistribution hazards model with were utilized to assess the association between injury and AF/AFL. Results. There were 130 reported AF/AFL cases, 90 of whom were injured and 40 were non-injured. The estimated cumulative incidence rates of AF/AFL for injured was higher compared to non-injured patients $(\mathrm{HR}=2.04 ; 95 \% \mathrm{CI}=1.44,2.87)$. After adjustment demographics and tobacco use, the association did not appreciably decrease $(\mathrm{HR}=1.90 ; 95 \% \mathrm{CI}=1.23,2.93)$. Additional adjustment for obesity, hypertension, diabetes, and vascular disorders, the association between injury and AF/AFL was no longer statistically significant (HR: 1.51; 95\% CI = 0.99, 2.52). Conclusion. Higher AF/AFL incidence rate was observed among deployed service members with combat injury compared to servicemembers without injury. The association did not remain significant after adjustment for cardiovascular-related covariates. These findings highlight the need for combat casualties surveillance to further understand the AF/AFL risk within the military population and to elucidate the potential underlying pathophysiologic mechanisms.
\end{abstract}

\section{Hosted file}

Main Document.pdf available at https://authorea.com/users/410862/articles/520080-traumaticinjury-and-atrial-fibrillation-among-deployed-service-members

\section{Hosted file}

Figure.pdf available at https://authorea.com/users/410862/articles/520080-traumatic-injuryand-atrial-fibrillation-among-deployed-service-members

\section{Hosted file}

Table.pdf available at https://authorea.com/users/410862/articles/520080-traumatic-injuryand-atrial-fibrillation-among-deployed-service-members 